\title{
Factors Influencing Consumer's Intention towards Online Grocery Shopping
}

\author{
Anis Shaira Sulastri, Nolila Mohd Nawi, Amin Mahir Abdullah, \\ Ismail Abd Latif \\ Department of Agribusiness and Bioresource Economics, Faculty of Agriculture, Universiti Putra Malaysia, \\ 43400 Serdang, Selangor, Malaysia
}

\begin{abstract}
Online platform nowadays has started to replace the traditional market and require consumers to change their buying habits and patterns extensively. Thus, the trend of having grocery delivered to the doorstep has been introduced to Malaysian consumers especially who lives in urban area. Previous studies have shown that online groceries are not consistently purchased by the consumers due to several reasons such as inconsistent quality and lack of sensory characteristics. However, there are still number of consumers who continuously shops groceries through online platform. Thus, the aim of this study is to determine factors influencing consumer's intention to shop groceries online. The primary data were collected using structured questionnaire in the form of online survey with 521 respondents in Klang Valley, Malaysia. Data collected were analyzed using descriptive analysis and factor analysis. The findings of the study showed that majority of the online grocery shoppers are female with the age ranged between 26-35 years old. Besides that, results from factor analysis revealed that perceived usefulness, satisfaction, perceived risk, perceived information accessibility and perceived ease of use are among factors that influenced consumer's intention towards online grocery shopping. Therefore, this study can be used to assist online grocery retailers to formulate effective strategies to gain more consumers' confidence to make use of online grocery shopping.
\end{abstract}

Keywords:-Grocery, online shopping, intention, factor analysis, Malaysian consumers

\section{INTRODUCTION}

The phenomenon of venturing online among Malaysian consumers has contributed to the increasing of urbanization and changing their lifestyles. The government efforts to shape and transform Malaysia into a digital economy have led to an active Internet use in the country. Along with this, online shopping is gradually becoming a trend among consumers in Malaysia over the last three years and almost half of them done shopping online at least once a month (PwC Total Retail, 2016). Furthermore, online shoppers have also increased their spending to the wider range of product categories and not just focus on specific product categories. A survey from Malaysian Communications and Multimedia Commission (2016) has reported the top three most preferred online shopping categories that have been purchased among Malaysian online consumers are apparel, travel and top-up prepaid phone. In addition, some of the online consumers were also interested in purchasing groceries through Internet. Thus, it shows that the traditional supermarket has been challenged by a wave of Internet grocery retailers.

The online grocery shopping concept in Malaysia has been introduced in mid-2000 with the service providers such as PasarBorong.com, SubangGrocer.com, CGdeMart.com and Citraspicemart.com (Paynter \& Lim, 2001; Ghazali et al., 2006; and Zaini et al., 2011). Unfortunately, the online grocery business at that moment did not get a good response and their existences are less known by the consumer (Muhammad et al., 2016). Year by year, increasing in ICT knowledge among Malaysians as well as changing in consumer's lifestyle, has provided an opportunity to boost local grocery market and motivate consumer to utilize online grocery shopping. Online grocers in a present day offered much better services to their customers in terms of product quality, delivery areas, promotions, security and safety of personal information and transactions as well as creating mobile applications. Tesco, HappyFresh and RedTick are among online grocers that currently have been developed to lead the trend and create consumers excitement in online grocery shopping.

In developed cities and places, online shopping for non-food products has taken off with higher penetration, unlikely the online shopping for grocery is still at infant stage especially in Malaysia. The online grocery retailers has expand their coverage and improving their service and offering to attract existing and 
potential customers. However, previous studies have shown that online groceries are not purchased consistently by consumers compared to other online products or services. There are few factors that have been observed as the reasons for the low uptake in online grocery shopping such as the quality of groceries product, the delivery charges and sensory characteristics problem (Ramus and Nielsen, 2005; Tsydybey, 2014; Seitz, 2013 \& Zaini et al., 2011). Despite the problems faced by consumers, there are still numbers of them that have continuously performed online grocery shopping. Therefore, this study was conducted to determine factors influencing consumers' intention towards online grocery shopping in Malaysia.

\section{LITERATURE REVIEW}

Online shopping among Malaysian consumers has shown positive trends since the existence of ecommerce business. Hence, an online grocery shopping concept has been introduced to shift consumer grocery shopping habits from traditional store to virtual store. According to past studies, online grocery shopping occur when consumers purchase or order grocery goods through the retailers' websites and the subsequent process including picking, packing and delivering grocery goods directly to consumers will be made by the grocery retailers itself (Raijas, 2002; Kurnia and Chien, 2003). Convenience and time saving is often recognized with the use of online grocery shopping among consumer because of its daily operations and hassle-free experience. Consumer does not need to go through several process that usually occur when making trips to physical store such as dressing up, worry about traffic, finding parking space, dealing with crowds and queuing, and carrying heavy groceries home from the supermarket (Ramus and Nielsen, 2005; Noor et al., 2011). However, there are some issues that hindering consumer to perform online grocery shopping. Consumer cannot directly inspect the quality of products and select the groceries by themselves especially for perishable goods such as meat, vegetable and fish. Besides that, consumers also concerned about the delivery fee charged by the retailers as well as the privacy and payment security issues (Huang and Opperwal, 2006).

Few academic researchers have examined and identified what are the factors that influenced consumers' intention to shop online. A study conducted by Tanadi et al. (2015) on online intention among Generation-Y in Malaysia found few factors influencing online shopping which are delivery risk, privacy risk, quality risk, time risk, convenience, product selection, ease of shopping and enjoyment. In a similar study, Rahman et al. (2014) claimed that cognitive, perceived usefulness and perceived ease of use had a positive impact on Malaysian consumers' intention towards e-shopping. According to Kurnia and Chien (2003), convenience and time saving are the major factors in online grocery shopping due to perceived usefulness of online shopping are relevant to the perceived benefits. Further study by Hansen (2005) found that simple and effective information and ordering procedure that are easy to understand and do not require high navigation skill and effort can influence customers to do online grocery shopping. Besides that, the impact of social factors such as family, friends, community or media also plays an important role on influencing consumers to shop online. This is consistent with a study by Choi (2013) that indicated social influence as one of the key determinants that affected repeat online grocery buying intention. Furthermore, the success of online business is often measured by the online customer satisfaction. A study among Taiwanese online customers found that satisfactions are one of the factors influencing online purchase intention (Tsai and Huang, 2007).

\section{METHODOLOGY}

This study is based on the Technology Acceptance Model that has been modified and expands to suits this study. Perceived Usefulness, Perceived Ease of Use, Perceived Risk, Social Influence and Satisfaction are among factors that predicted to have influence towards consumer intention on online grocery shopping. Online questionnaire were developed and distributed via personalized electronic mail and online private message to the targeted respondents. The primary data have been obtained from 521 online grocery shoppers in Klang Valley area by using purposive sampling method. There are two types of analysis used to analyze factors influencing consumers' intention towards online grocery shopping which is descriptive analysis and factor analysis. Descriptive analysis was used to quantify the demographic of the study while factor analysis was used to determine the latent factors underlying consumers' intention towards online grocery shopping.

\subsection{Respondents' Socio Demographic Profiles}

\section{RESULTS AND DISCUSSION}

Table 1 illustrates the respondents' demographic profile. In this study, the results showed that most of the respondents were female with $83.1 \%$ while $16.9 \%$ of the remaining respondents were male. The majority of the respondents were aged between $26-35$ years old with $69.7 \%$ and $63.1 \%$ of the respondents were married. Finally, respondents having a monthly income group within the range of RM4,501 to RM6,000 comprised the majority income group (30.3\%) and most of the respondents were from a household between three to four people $(45.3 \%)$. 
Table 1: Summary of Respondents Background

\begin{tabular}{|l|c|l|c|}
\hline Characteristic & Percentage & Characteristic & Percentage \\
\hline Gender & & Household Size & \\
\hline Male & 16.9 & $1-3$ & 26.9 \\
\hline Female & 83.1 & $3-4$ & 45.3 \\
\hline & & $5-6$ & 24.2 \\
\hline Age & & 7 above & 3.6 \\
\hline Below 25 & 13.1 & & \\
\hline $26-35$ & 69.7 & Income (RM) & \\
\hline $36-45$ & 13.4 & Below 3000 & 11.5 \\
\hline $46-55$ & 3.3 & $3001-4500$ & 18.4 \\
\hline Above 56 & 0.6 & $4501-6000$ & 30.3 \\
\hline & & $6001-7500$ & 11.3 \\
\hline Marital Status & & $7501-9000$ & 14.6 \\
\hline Single & 31.7 & Above 9001 & 13.8 \\
\hline Married & 63.1 & & \\
\hline Widowed & 5.2 & & \\
\hline
\end{tabular}

Table 2 shows the results of respondents' experience towards using online grocery shopping. Majority of the respondents in this study have performed online grocery shopping at least once which accounted for $24.6 \%$ of the total respondents followed by once a week with $23.8 \%$. The amount spent by respondents for grocery product is about RM100 to RM150 made up $32.2 \%$ of the respondents. Only $8.3 \%$ of the respondents have spent on online grocery shopping amount more than RM200. Meanwhile, among 521 of respondents, majority of them used credit card $(41.7 \%)$ and debit card $(40.5 \%)$ to make their payments for their grocery purchases. The reasons why the respondents' purchased groceries through online shopping are because of convenience $(81.0 \%)$ and time saving $(62.4 \%)$.

Table 2: Respondents' experience towards online grocery shopping

\begin{tabular}{|l|c|c|}
\hline \multicolumn{1}{|c|}{ Characteristics } & Frequency & Percentage \\
\hline Frequency of purchasing groceries online & & \\
\hline Once & 128 & 24.6 \\
\hline Once a week & 124 & 23.8 \\
\hline Rarely & 105 & 20.2 \\
\hline Once a month & 75 & 14.4 \\
\hline Used to but not anymore & 57 & 10.9 \\
\hline More than once a month & 27 & 5.2 \\
\hline Once a fortnight & 5 & 1.0 \\
\hline & & \\
\hline Amount Spend Per Purchase & & \\
\hline RM100 - RM150 & 168 & 32.2 \\
\hline RM50 - RM100 & 163 & 31.3 \\
\hline RM150 - RM200 & 89 & 17.1 \\
\hline Less than RM50 & 58 & 11.1 \\
\hline More than RM200 & 43 & 8.3 \\
\hline & & \\
\hline Mode of Payment & & \\
\hline Credit card & 217 & 41.7 \\
\hline Debit card & 211 & 40.5 \\
\hline Cash on delivery & 136 & 26.1 \\
\hline Online banking transfer & 92 & 17.7 \\
\hline Other & 6 & 1.2 \\
\hline PayPal & 4 & 0.8 \\
\hline
\end{tabular}




\subsection{Factor Analysis}

In this study, the adequacy of the sample is measured by Kaiser-Meyer-Olkin (KMO) and Bartlett's Test of Sphericity was used to measure the strength of the relationship or correlation between all variables. According to Table 3 , the result of KMO test was 0.885 indicates that the sampling adequacy value was great and factor analysis can be carried out.

Table 3: KMO and Bartlett Test

\begin{tabular}{|l|l|r|}
\hline Kaiser-Meyer-Olkin Measure of Sampling Adequacy & .885 \\
\hline \multirow{3}{*}{ Bartlett's Test of Sphericity } & Approx. Chi-square & 7285.755 \\
\cline { 2 - 3 } & d.f & 253 \\
\cline { 2 - 3 } & Sig. & .000 \\
\hline
\end{tabular}

After the varimax rotation of the respondents' responses to the 38 statements relating to factors influencing consumers' intention towards online grocery shopping, the factor loading from the exploratory factor analysis was obtained and presented in Table 4 . The factor analysis of 23 statements was conducted and factors are then ranked according to the proportion of variance explained. In this study, five latent factors which influence consumers' intention towards online grocery shopping were identified. The five latent factors which accounted about $70.842 \%$ of the total variance are summarized as follows.

Table 4: Factors Influencing Consumer's Intention towards Online Grocery Shopping

\begin{tabular}{|l|l|l|l|l|l|}
\hline \multirow{2}{*}{ Items } & \multicolumn{4}{|c|}{ Factor Loadings } \\
\cline { 2 - 5 } & F1 & F2 & F3 & F4 & F5 \\
\hline Perceived Usefulness & & & & & \\
\hline $\begin{array}{l}\text { Reducing the hassle in terms of traffic congestion } \\
\text { and finding parking space }\end{array}$ & 0.846 & & & & \\
\hline $\begin{array}{l}\text { Reducing the hassle in terms of store crowds and } \\
\text { queuing during payment }\end{array}$ & 0.842 & & & & \\
\hline $\begin{array}{l}\text { Reducing the monetary cost of traditional } \\
\text { shopping }\end{array}$ & 0.802 & & & & \\
\hline $\begin{array}{l}\text { Reducing the efforts in travelling, walking, } \\
\text { parking, waiting and carrying items }\end{array}$ & 0.800 & & & & \\
\hline Online grocery shopping saves much time & 0.689 & & & & \\
\hline Online grocery shopping allows shopping quickly & 0.646 & & & & \\
\hline Variance (\% of variance explained) & $\mathbf{2 0 . 2 2 9}$ & & & & \\
\hline & & & & & \\
\hline Satisfaction & & 0.820 & & & \\
\hline Received information about new products & & 0.800 & & & \\
\hline Received special offers & & 0.797 & & & \\
\hline Satisfied with the customer support and services & & 0.747 & & & \\
\hline $\begin{array}{l}\text { Condition and quality of grocery items delivered } \\
\text { are good }\end{array}$ & & 0.705 & & & \\
\hline Satisfied with the delivery time slot given & & 0.656 & & & \\
\hline The quality of items provided online are good & & $\mathbf{1 7 . 3 8 6}$ & & & \\
\hline Variance (\% of variance explained) & & & & & \\
\hline & & & & & \\
\hline Perceived Risk & & & & & \\
\hline $\begin{array}{l}\text { Concerned if might not receive the product } \\
\text { purchased }\end{array}$ & & & 0.871 & & \\
\hline Concerned with the incorrect items received & & & & & \\
\hline $\begin{array}{l}\text { Concerned with the quality of the product } \\
\text { purchased }\end{array}$ & & & & & \\
\hline $\begin{array}{l}\text { Concerned with the punctuality of the delivery } \\
\text { time }\end{array}$ & & & & & \\
\hline Variance (\% of variance explained) & & & & \\
\hline Perceived Information Accessibility & & & & \\
\hline Gets more product information & & & & \\
\hline Get broader selections of products & & & & \\
\hline Ding & & & & \\
\hline
\end{tabular}




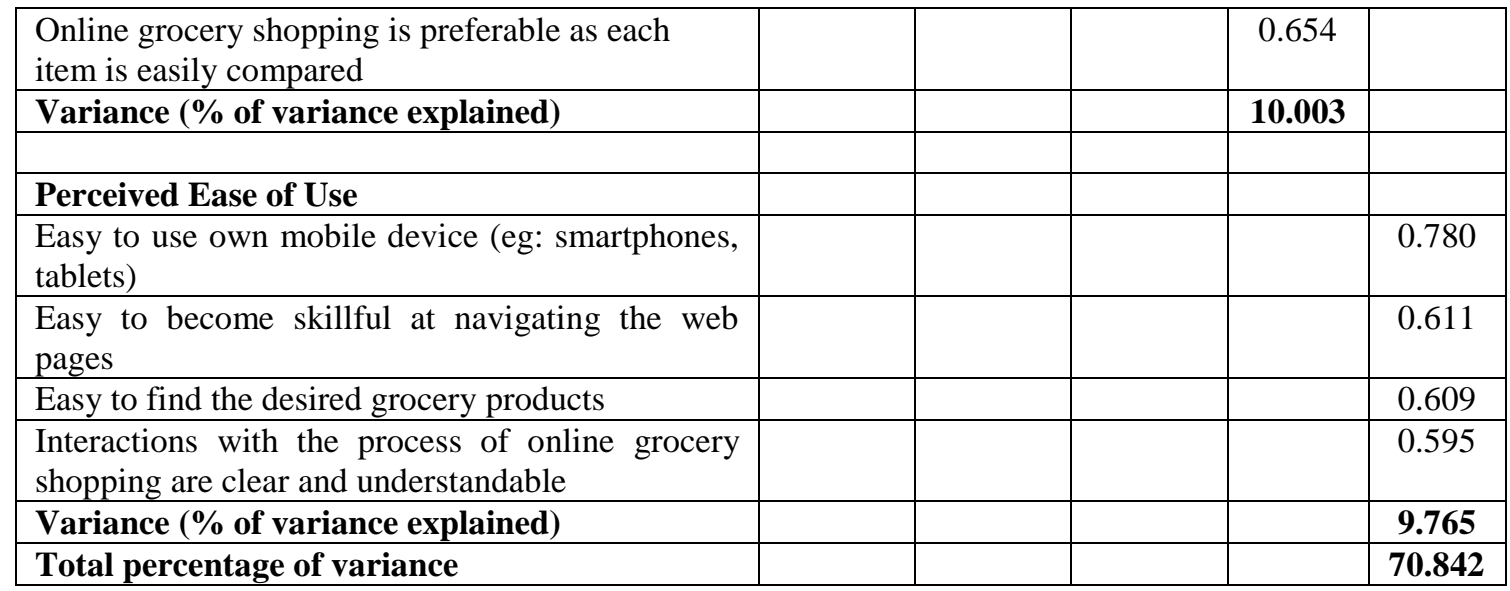

The first factor was categorized as Perceived Usefulness with a total variance explained was $20.229 \%$ and comprised of six significant items underlying the same factor. These six items were concerned on reducing consumer hassle in terms of traffic congestion, finding parking space, store crowds and queuing, reducing cost and efforts of travelling, time saving and allow consumer to do grocery shopping more quickly. The second factor was categorized as Satisfaction as all items contributing to satisfaction respondents derived when using online grocery shopping. It comprised of six significant items in this factor with a total variance explained was $17.386 \%$. These six items were implies on consumer satisfaction on using online grocery in terms of receiving new information and special offers, satisfied with the customer support and services, the condition and quality of grocery goods as well as the delivery time slot. Perceived Risk is the third factor uncovered in the factor analysis. This factor comprised of four significant items underlying the same factor, accounted for $13.459 \%$ of the total variance explained. From this study, it is suggested that consumers are very concern if they do not receive the products or receiving incorrect items, they concern about the quality of the product as well as the punctuality of the delivery time. The next factor consists of statements which can be categorized as Perceived Information Accessibility. It comprised of three significant items in this factor with a total variance explained was $10.003 \%$. The statements in this factor include consumers can get more information about the grocery product, wide selection of products and easily compared for every each of grocery product. Finally, the last factor was categorized as Perceive Ease of Use comprised of four significant items, accounted for $9.765 \%$ of the total variance explained. These four items were concerned on consumers ability of using mobile device to make online grocery shopping, skillful to navigate the web page, easy to find product in the website and able to interact with the process of online grocery shopping.

\section{CONCLUSION}

The aim of this research is to uncover the factors influencing consumers' intention towards online grocery shopping. The factors which are significant in predicting the intention of Malaysian consumers to shop groceries online are: Perceived Usefulness, Satisfaction, Perceived Risk, Perceived Information Accessibility and Perceived Ease of Use. These five factors explained about $70.842 \%$ of the total variance. Besides that, this study also identified that women are more likely to shop groceries online and the major online grocery shoppers are the young consumers, and these might be because they are more tech-savvy and driving the online market rather than older consumers.

The emergence of the Internet for the past few years has brought to the development of online grocery shopping in the world and changed consumers' pattern habit in purchasing groceries. Online grocery shopping in Klang Valley was still relatively small as compared to other online shopping. However, those who used to shop grocery through online said they had an enjoyable experience and would most probably do it again in the future. Therefore, it is important for the online grocery retailers to provide their customer with seamless shopping experience from ease of making purchase to successful delivery and ensure customers' satisfaction to guarantee the competitiveness of the industry.

\section{REFERENCES}

[1]. PwC Total Retail. (2016, February). They say they want a revolution. Retrieved from https://www.pwc.com/

[2]. Malaysian Communications and Multimedia Commission. (2016). Internet users surveys 2016.Cyberjaya: Malaysian Communications and Multimedia Commission.

[3]. Paynter, L., \& Lim, J. (2001). Drivers and impediments to e-commerce in Malaysia. Malaysian Journal of Library \& Information Science, 6(2), 1-19. 
[4]. Ghazali, E., Mutum, A.D., \& Mahbob, N.A. (2006). Attitude towards online purchase of fish in urban Malaysia: An ethnic comparison. Journal of Food Products Marketing, 12(4), 109-128.

[5]. Zaini, Z.M.M., Ramli, N., Ghani, F.A., Samsudin, A., Hamid, M., Jusoff, K., Ngali, N., Rahmat, N., Khalid, K., \& Musa, M. (2011). Online grocery shopping: The affect of time availability on Malaysian consumer preference. World Applied Science Journal, 12, 60-67.

[6]. Muhammad, N.S., Sujak, H., \& Rahman, S.A. (2016). Buying groceries online: The influence of electronic service quality (eServQual) and situational factors. Fifth International Conference on Marketing and Retailing ( $5^{\text {th }}$ INCOMaR) 2015, Procedia Economics and Finance, 37, 379- 385.

[7]. Ramus, K. \& Nielsen, N. A. (2005). Online grocery retailing: What do consumers think? Internet Research, 15(3), 335-352.

[8]. Tsydybey, N. (2014). Consumer intentions to buy grocery products online: A comparison between the Netherlands and Russia. (Master's Thesis, Tilburg University, Netherlands).

[9]. Seitz, C. (2013, June). E-grocery as new innovative distribution channel in the German food retailing. International Conference, Zadar, Croatia. Retrieved from https://ideas.repec.org/h/tkp/mklp13/125-133.html

[10]. Raijas, A. (2002). The consumer benefits and problems in the electronic grocery store. Journal of Retailing and Consumer Services, 9(2), 107-113.

[11]. Kurnia, S., \& Chien, A.J. (2003). The acceptance of online grocery shopping. In Proceedings 16th Bled eCommerce Conference eTransformation, 219-233.

[12]. Noor, A.M., Zaini, Z.M.M., Jamaluddin, M.R., \& Zahari, M.S.M. (2011). Exploratory studies on online grocery shopping. $3^{\text {rd }}$ International Conference on Information and Financial Engineering,

[13]. Huang, Y., \& Oppewal, H. (2006). Why consumers hesitate to shop online: An experimental choice analysis of grocery shopping and the role of delivery fees. International Journal of Retail \& Distribution Management, 34(4/5), 334-353.

[14]. Tanadi, T., Samadi, B., \& Gharleghi, B. (2015). The impact of perceived risks and perceived benefits to improve an online intention among Generation-Y in Malaysia. Asian Social Science, $\quad 11(26), 226-$ 238.

[15]. Rahman, M.K., Jalil, M.A., Mamun, A.A., \& Robel, S.D. (2014). Factors influencing Malaysian consumers' intention towards e-shopping. Journal of Applied Sciences, 14, 2119-2128.

[16]. Hansen, T. (2005). Consumer adoption of online grocery buying: A discriminant analysis. International Journal of Retail \& Distribution Management, 33(2), 101-121.

[17]. Choi, Y. (2013). A structural equation model of the determinants of repeat purchase behaviour of online grocery shoppers in the UK (Doctoral thesis, Newcastle University, England, United Kingdom).

[18]. Tsai, P.L., \& Huang, C.H. (2007). Openness, growth and poverty: The case of Taiwan. World Development, 35(11), 1858-1871. 